\title{
Maternal complications and neonatal outcomes in oligohydramnios
}

\author{
Jahanara Rahman*, Shahana Pervin \\ Department of Obstetrics and Gynaecology, Dhaka National Medical College, Dhaka, Bangladesh
}

Received: 05 January 2022

Accepted: 20 January 2022

\author{
*Correspondence: \\ Dr. Jahanara Rahman, \\ E-mail: jahanararahman64@gmail.com
}

Copyright: () the author(s), publisher and licensee Medip Academy. This is an open-access article distributed under the terms of the Creative Commons Attribution Non-Commercial License, which permits unrestricted non-commercial use, distribution, and reproduction in any medium, provided the original work is properly cited.

\begin{abstract}
Background: Oligohydramnios is a condition of abnormally low amniotic fluid volume which is associated with adverse pregnancy outcomes. The objectives of the study were to find out the prevalence of oligohydramnios, to observe maternal complications associated with oligohydramnios, to detect neonatal morbidities and mortalities in oligohydramnios.

Methods: A cross sectional, descriptive study was carried out in the in-patient department of obstetrics and gynaecology at Dhaka national medical college hospital between March 2016 and February 2017.

Results: In this study 64 women had oligohydramnios among 1240 pregnant mothers admitted for delivery in obstetrics and gynaecology department and prevalence was $5.2 \%$. Sixty six percent occurrence of oligohydramnios was due to premature rupture of membranes. The mean maternal age was $24.82 \pm 3.71$ years. Maternal infections like, Respiratory tract infection (15\%), vaginitis (20\%), UTI (31\%), hyperpyrexia (7\%) and maternal systemic illness like, hypertension and diabetes mellitus were also noticed in $7 \%$ and $5 \%$ of the population. Majority $(71 \%)$ of the mothers delivered by caesarian section and of them $31.82 \%$ was due to foetal distress. Unfavorable neonatal outcome was noticed as low birth weight (LBW) (28\%), respiratory depression (32\%), perinatal death (14\%) and NICU admission (29\%).

Conclusions: No significant association was found between maternal systemicillness and oligohydramnios. Whereas maternal infection was found as a significantfactor leading to PROM related oligohydramnios. Occurrence of caesarian sections and unfavourable neonatal outcomes were found high in oligohydramnios.
\end{abstract}

Keywords: Oligohydramnios, Maternal complications, Neonatal outcome

\section{INTRODUCTION}

Oligohydramnios is one of the common complications of pregnancy where amniotic fluid is diminished in amount. Amniotic fluid provides a supportive as well as protective environment for fetal development during pregnancy. Normally, the level of amniotic fluid is at its highest around 36 weeks of pregnancy and gradually this level decreases as birth nears. Oligohydramnios is defined when the amniotic fluid index (AFI) seen on ultrasound measures less than $5 \mathrm{~cm}$ (normal index is $5-25 \mathrm{~cm}$ ) and the maximum vertical pocket (MVP) is less than $2 \mathrm{~cm} .{ }^{1,2}$ The incidence of oligohydramnios varies from $2 \%$ to $14 \% .^{3-5}$ It occurs in many high-risk cases of mothers, like chronic hypertension, preeclampsia, diabetes, lupus, post-term pregnancy and uteroplacental insufficiency. On the other hand,congenital anomalies of foetus, such as anomalies of the kidneys including congenital absence of renal tissue, obstructive uropathy or decreased renal perfusion are also contributing factors. However premature rupture of membranes is one of the common causes of oligohydramnios and many are idiopathic too. ${ }^{6,7}$ Decreased amniotic fluid volume is especially of concern when it occurs in conjunction with foetal structural anomalies, intrauterine growth retardation, prolonged pregnancies, maternal and neonatal worse outcome. Usually when oligohydramnios is diagnosed at term, pregnancy is terminated even in otherwise uncomplicated pregnancies by induction of labor or caesarean section. ${ }^{8}$ Diminished amniotic fluid increases the rate of caesarian delivery and mostly due to non-reassuring foetal heartrate. ${ }^{9}$ Other indications of caesarian sections are malposition, malpresentation and other obstetric causes. 
Amniotic fluid volume is an important parameter in the assessment of fetal well-being. Often oligohydramnios is associated with adverse perinatal outcomes, like foetal distress, stillbirth, meconium aspiration syndrome, low birth weight and foetal malformation. It increases rate of admission to neonatal intensive care and neonatal morbidity and mortality. ${ }^{10,11}$

\section{METHODS}

A prospective cross-sectional study was carried out in the In-patient department of obstetrics and gynaecology at Dhaka national medical college hospital for the period of one year between March 2016 and February 2017. Pregnant women with gestational age beyond 36 weeks with oligohydramnios detected by ultrasonography were recruited for this study purposively. With the use of realtime B-scanning, amniotic fluid index (AFI), the sum of the vertical diameter of the largest pocket in each of the four quadrants was measured. Oligohydramnios was defined as an amniotic fluid index (AFI) $\leq 5 \mathrm{~cm}$. A detailed obstetric history was taken by face-to-face interviewing pregnant mothers. General, systemic and obstetrical examinations were done. Parameters of foetal wellbeing were recorded. APGAR score of the newborn was noted at 1 and 5 minutes of birth. Data was analyzed in SPSS version 19 and statistical significance was calculated using Chi-square test. $\mathrm{P}<0.05$ with $95 \%$ confidence interval (CI) was considered significant.

\section{Inclusion criteria}

Pregnant women of gestational age 36 weeks or more admitted with oligohydramnios detected by ultrasonography were included in the study.

\section{Exclusion criteria}

Those patients whose gestational age was less than 36 weeks and had multiple pregnancy were excluded from the study.

\section{RESULTS}

During this hospital-based study period 1240 pregnant women were admitted in the department of obstetrics and gynaecology for delivery. Among them 64 individuals had oligohydramnios at term detected by ultrasonography. The prevalence of oligohydramnios was found 5.2\%. Among them $66 \%$ were secondary to PROM and $34 \%$ had intact amniotic membranes. The mean maternal age was $24.82 \pm 3.71$ years. Women developing oligohydramnios had hypertension $(7 \%)$, diabetes $(5 \%)$, respiratory tract infection $(15 \%)$, urinary tract infection $(3 \%)$, hyperpyrexia (7\%), and vaginitis (20\%). Majority (71\%) of the babies were delivered by caesarian section. Others were delivered spontaneously (26\%) and by medical induction (3\%). Higher percentage of caesarean sections were performed due to foetal distress $(31.82 \%)$. Malposition and nonengagement of presenting part $(22.73 \%)$, malpresentation
(11.36\%), dry labour (11.36\%), low birth weight (6.89\%), history of previous twice caesarian section (4.54\%), prolonged labour $(2.27 \%)$ were other indications of caesarean delivery. Adverse neonatal outcome was noticed as LBW (28\%), birth asphyxia (32\%), congenital malformation $(9.37 \%)$, neonatal jaundice $(46.87 \%)$, admission to NICU (29\%), perinataldeath (14\%) due to respiratory depression $(77.78 \%)$ as well as septicemia $(22.22 \%)$.

Table 1: Characteristics of mothers developing oligohydramnios.

\begin{tabular}{|lll|}
\hline Variables & N & $\begin{array}{l}\text { Percentage } \\
(\%)\end{array}$ \\
\hline Maternal age (Years) & & \\
\hline$<20$ & 6 & 9.37 \\
\hline 20 to 25 & 28 & 43.75 \\
\hline$>25$ to 30 & 28 & 43.75 \\
\hline$>30$ & 2 & 3.13 \\
\hline Maternal occupation & & \\
\hline Home maker & 55 & 85.94 \\
\hline service & 4 & 6.25 \\
\hline Student & 2 & 3.13 \\
\hline Others & 3 & 4.68 \\
\hline Parity & & \\
\hline Primi & 44 & 69.0 \\
\hline Multi & 20 & 31.0 \\
\hline
\end{tabular}

Table 2: Characteristics of newborns of oligohydramnios.

\begin{tabular}{|lll|}
\hline Variables & $\mathbf{N}$ & $\begin{array}{l}\text { Percentage } \\
(\%)\end{array}$ \\
\hline Sex & & \\
\hline Male & 33 & 52.0 \\
\hline Female & 31 & 48.0 \\
\hline Birth weight $(\mathbf{k g})$ & & \\
\hline$<2.5$ & 18 & 28.0 \\
\hline $2.5-3$ & 30 & 47.0 \\
\hline$>3$ & 16 & 26.0 \\
\hline
\end{tabular}

Table 3: Distribution of neonates according to complications, $(n=64)$.

\begin{tabular}{|c|c|c|}
\hline $\begin{array}{l}\text { Birth asphyxia } \\
\text { (APGAR scoring by } 5 \\
\text { minutes) }\end{array}$ & $\mathbf{N}$ & $\begin{array}{l}\text { Percentage } \\
(\%)\end{array}$ \\
\hline $\begin{array}{l}\text { 0-3 (severe } \\
\text { depression) }\end{array}$ & 4 & 6.0 \\
\hline $\begin{array}{l}\text { 4-6 (mild to moderate } \\
\text { depression) }\end{array}$ & 16 & 26.0 \\
\hline LBW & 18 & 28.0 \\
\hline Septicemia & 6 & 9.38 \\
\hline Jaundice & 30 & 46.87 \\
\hline Birth defect & 6 & 9.37 \\
\hline Admission to NICU & 18 & 29.0 \\
\hline Neonatal death & 9 & 14.06 \\
\hline
\end{tabular}




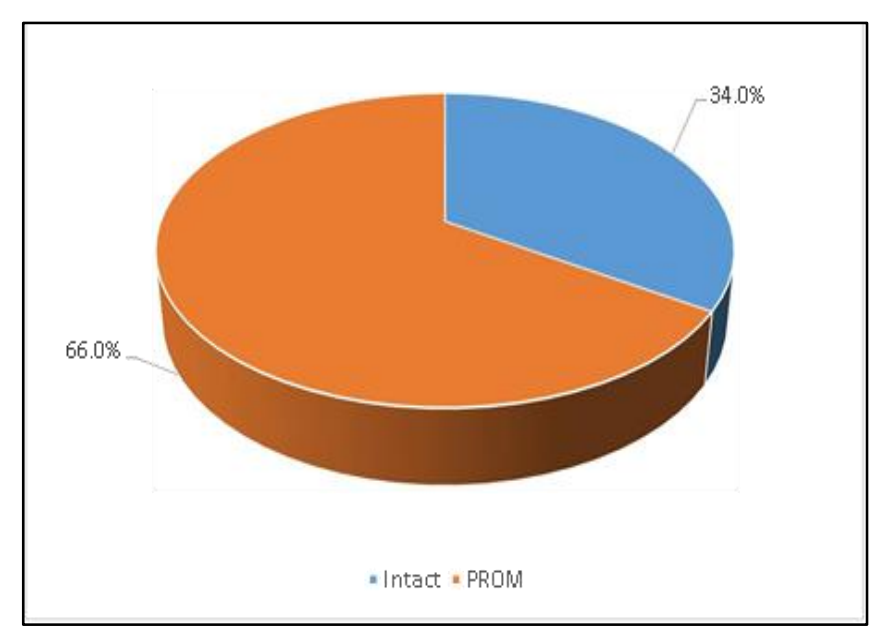

Figure 1: Distribution of mothers according to status of membranes.

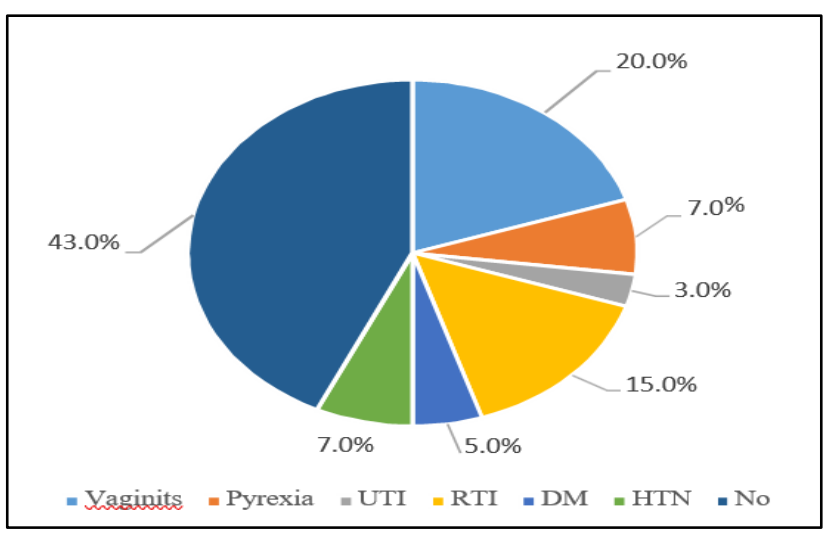

Figure 2: Distribution of mothers according to complications in pregnancy.

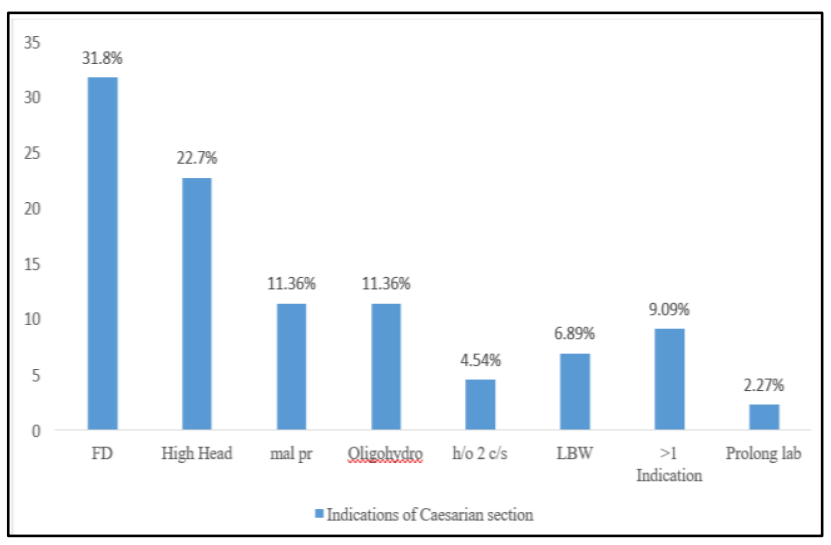

Figure 3: Indications of caesarian section.

\section{DISCUSSION}

This one-year study conducted at In-patient department of Dhaka national medical college Hospital found the prevalence of oligohydramnios $5.2 \%$ whereas other studies found $2.3 \%, 11 \%$ and $14 \% .{ }^{3-5}$ Worldwide, there is a difference in the prevalence of oligohydramnios and this could be due to the difference in the population studied. Current study found higher percentage (66\%) of oligohydramnios was secondary to premature rupture of membranes (Figure 1). This study found some high-risk mothers among this population of developing oligohydramnios. Hypertension wasfound in $7 \%$ mothers of oligohydramnios (Figure 2), whereas another author found $22.1 \%$ hypertensive mothers developing oligohydramnios. ${ }^{11}$ Hypertension causes poor placental perfusion and thereby decreased amniotic fluid production. In a study O'Brien et al found higher percentage of worse amniotic fluid status in the presence of severe preeclamptic (PE) cases. ${ }^{12}$ Current study found fewer percentage (5\%) of diabetic mothers developing diminished amniotic fluid (Figure 2) Almost similar results (5.37\%) were observed by Christine et al in their study. ${ }^{13}$ On the other hand other authors, Hou et al and Jodi et al found a significantly higher incidence of preexisting or gestational diabetes mellitus in oligohydramnios. ${ }^{14,15}$ Though polyhydramnios and oligohydramnios are the well-established complications in diabetic pregnant mothers. But several studies found amniotic fluid volumeis minimally or not at all affected in gestational diabetes regardless of glycemic control. This study found maternal complications like, respiratory tract infection (15\%), urinary tract infection (3\%), pyrexia (7\%) and vaginitis $(20 \%)$ among the mothers with oligohydramnios secondary to PROM (Figure 2). Vaginitis was found as a highly statistically significant $(\mathrm{p}=0.0001)$ factor of PROM induced oligohydramnios. Other studies reported genitourinary infections as an important risk factor of PROM and oligohydramnios. ${ }^{16,17}$ Infact, genitourinary infections may cause ascending infection, chorioamnionitis and increasing fragility of the amniotic membrane which induces PROM. The present study showed high occurrence $(71 \%)$ of Caesarian section $(\mathrm{p}=0.003)$. Foetal distress was found as the commonest $(31.80 \%)$ indication of caesarian section (Figure 3) which is of no difference from the results $(32.73 \%)$ of Surayapalem et al. ${ }^{16}$ Other authors also found women with oligohydramnios have a higher risk of caesarian delivery for non-reassuring foetal heart rate. ${ }^{18,19}$ Beside this, to avoid other complications like chorioamnionitis, prolonged labour, placental insufficiency and for malpresentations caesarian sections were performed in current study (Figure 3). This study found $28 \%$ of the newborns are LBW (Table 3). Anna et al and Hou et al also observed in their studies increased percentage of babies with intrauterine growth restrictions in oligohydramnios. ${ }^{4,14}$ More than thirty eight percent babies were found LBW born to mothers with oligohydramnios in a study in India by Biradar et al. ${ }^{5}$ Foetal growth restrictions havebeen found associated with oligohydramnios among several maternal conditions such as utero-placental insufficiency, hypertension, preeclampsia, diabetes, chronic hypoxia, rupture of amniotic membranes, dehydration and post-term gestation.

Even oligohydramnios is independently associated with higher risk of intrauterine growth restriction. ${ }^{4}$ Current 
study found birth asphyxia among $31.25 \%$ newborns (Table 3). Brian et al also found $48 \%$ low APGAR score babies born to mothers with oligohydramnios. ${ }^{3}$ In present study increased percentage of asphyxiated babies was due to their LBW. Lengthening of PROM delivery interval $(62.5 \%)$ was found as another important factor of birth asphyxia in oligohydramnios secondary to PROM in this study. Septicaemia was noticed among $9.38 \%$ newborns all of which from PROM induced oligohydramnios. Neonatal jaundice was detected in $46.87 \%$ of newborns majorityof which were LBW babies. More than nine percent birth defect babies were found in current study of which gross congenital anomaly and minor defects $6 \%$ and $4 \%$ respectively. In another study overall rate of foetal malformation was $11 \%$ and that of lethal malformations $4.8 \% .{ }^{11}$ Twenty nine percent worse newborns needed to be admitted to NICU (Table 3). Biradar et al found $40 \%$ newborns had to be admitted to NICU among the babies of Oligohydramnios inhis studies. ${ }^{5}$ Perinatal mortality (14\%) of this study was almost similar results $(16 \%)$ to a study of Golan et al. ${ }^{11}$ Leading factors of death in this study are birth asphyxia (66.67\%) and septicaemia (22.22\%). Very near results of perinatal mortality due to RDS $(53 \%)$ and sepsis $(27 \%)$ were noticed by Padmaja et al in their study. ${ }^{20}$

\section{Limitation}

The sample size of population in the current study was small and limited to one hospital. Therefore, it could not represent the outcome of oligohydramnios of whole pregnant population of Bangladesh. Many newborns had to be referred to another hospital soon after delivery for better neonatal care, thereby exact percentage of morbidity could not be mentioned. Large scale studies of longer duration with strict follow up are necessary to get a real picture of neonatal outcomes in oligohydramnios in our country.

\section{CONCLUSION}

To conclude, maternal systemic illness was not found strongly associated with oligohydramnios. Respiratory and genitourinary infections were noticed as a significant maternal factor for oligohydramnios secondary to PROM. Women with oligohydramnios were more likely to had low birth weight and asphyxiated babies. Rate of caesarian section was significantly high in oligohydramnios. Foetal distress was the commonest indication of caesarian sections. Oligohydramnios secondary to PROM results in more unfavourable perinatal outcomes.

\section{ACKNOWLEDGEMENTS}

Author would like to thanks to colleagues of the department of obstetrics and gynaecology for their extreme cooperation and inspiration to complete my work. I also pay thanks to my colleagues of Neonatology who is in one way or the other way graciously extended support to me.
Funding: No funding sources

Conflict of interest: None declared

Ethical approval: The study was approved by the Institutional Ethics Committee

\section{REFERENCES}

1. Brace RA. Physiology of amniotic fluid volume regulation. Clin Obstet Gynecol. 1997;40:280-9.

2. Locatelli A, Zagarella A, Toso L, Assi F, Ghidini A, Biffi A. Serial assessment of amniotic fluid index in uncomplicated term pregnancies: prognostic value of amniotic fluid reduction. J Matern Neonatal Med. 2004;15:233-6.

3. Brian M. Pregnancy outcomes after antepartum diagnosis of oligohydramnios at or beyond 34 weeks' gestation. Am J Obstet Gynecol. 2000;182(4):909-12.

4. Anna L, Patrizia V, Laura T, Maria V, John C. P, Alessandro G. Perinatal outcome associated with oligohydramnios in uncomplicated term pregnancies. Arch Gynecol Obstetr. 2004;269:1303.

5. Biradar KD, Shamanewadi AN. Maternal and perinatal outcome in oligohydramnios: study from a tertiary care hospital, Bangalore, Karnataka, India. Int J Reprod Contracept Obstet Gynecol, 2016;5(7):2291-9.

6. Cunningham FG, Williams JW. Williams Obstetrics. McGraw-Hill Medical. 2010. Available at:

https://www.ncbi.nlm.nih.gov/nlmcatalog/1015106 55. Accessed on $10 \mathrm{Feb} 2020$.

7. Fischer RL. Amniotic fluid: physiology and assessment. Glob Libr Women's Med. 2009. Available at: https://doi.org/10.3843/GLOWM.10208. Accessed on 10 Feb 2020.

8. David M. Sherer. A Review of Amniotic Fluid Dynamics and the Enigma of Isolated Oligohydramnios. Am J Perinatol. 2002;19(5):25366.

9. Lester Figueroa et al. Oligohydramnios: a prospective study of fetal, neonatal and maternal outcomes in low- middle income countries. Reproductive Health volume. 2020;17:19.

10. Nabhan AF, Abdelmoula YA. Amniotic fluid index versus single deepest vertical pocket as a screening test for preventing adverse pregnancy outcome. Cochrane Database Syst Rev. 2008;2008(3):CD006593.

11. Golan A, Lin G, Evron S, Niv D, David M.P. Oligohydramnios: Maternal Complications and Fetal Outcome in 145 Cases. Gynecol Obstet Invest. 1994;37:91-5.

12. O’Brien JM, Mercer BM, Friedman SA, Sibai BM. Amniotic fluid index in hospitalized hypertensive patients managed expectantly. Obstet Gynecol. 1993;82(2):247-50.

13. Christine F, Oded L. Does gestational diabetes affect 
amniotic fluid characteristics? Volume 204, 1 St. Luke's-Roosevelt Hospital Center, New York, NY. 2011.

14. Lei H, Xin W, Susan H, Liying Z, Yan R, Weiyuan Z. Delivery modes and perinatal outcomes after diagnosis of Oligohydramnios at term in China. Maternal-Fetal Neonatal Med. 2020;33(14):240814.

15. Jodi S, Lawrence N, Donald DM, Kenneth JL. Correlation between amniotic fluid glucose concentration and amniotic fluid volume in pregnancy complicated by diabetes. Am J Obstet Gynecol. 2000;182(4):901-4.

16. Surayapalem S, Cooly V, Salicheemala B. A study on maternal and perinatal outcome in premature rupture of membranes at term. Int $\mathbf{J}$ Reprod Contracept Obstet Gynecol. 2017;6(12):5368-72.

17. Vogel JP, Lee AC, Souza JP. Maternal morbidity and
Preterm birth in 22 Low and Middle-income countries: a secondary dataset. BMC pregnancy Childbirth. 2014;14:56.

18. Gibbs R, Karlan B, Haney A, Nygaard I. Danforth's obstetrics and gynecology. $10^{\text {th }}$ ed. Philadelphia: Lippincott Williams and Wilkins. 2008.

19. Gabbe SG, Niebyl JR, Simpson JL. Obstetrics: Normal and problem pregnancies. $5^{\text {th }}$ ed: Ed: ChurchillLivingstone. 2007.

20. Padmaja J, Swarupa K. Maternal and Perinatal Outcome in Premature Rupture of Membranes at TermPregnancy. IAIM. 2018;5(4):87-91.

Cite this article as: Rahman J, Pervin S. Maternal complications and neonatal outcomes in oligohydramnios. Int J Reprod Contracept Obstet Gynecol 2022;11:310-4. 